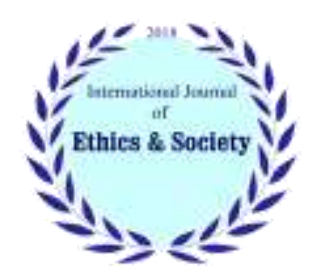

International Journal of Ethics \& Society (IJES)

Journal homepage: $\underline{\text { www.ijethics.com }}$

Vol. 2, No. 4 (2021)

(Original article)

\title{
Mapping Customers' Mind Value to Avoid Pseudo Needs in Con- suming Drinks during Flight based on Ethical Marketing Approach
}

\author{
Alireza Fayazi ${ }^{a}$, Abdullah Naami ${ }^{b^{*}}$, Reza Aghamusa ${ }^{b}$ \\ a) Ph.D. Student of Business Management, Islamic Azad University, South Tehran Branch, Tehran, Iran. \\ b) Dept. of Business Management, Islamic Azad University, South Tehran Branch, Tehran, Iran.
}

\section{Abstract}

Background: One of the important aspects of ethical marketing is avoiding making or reinforcing pseudo need in customers. Therefore, marketing studies may use methods which identify customers' fundamental mind values in consuming commodity and services to provide products without stimulating, harmful and extra effects which satisfy customers. Therefore, the current study aims at investigating and drawing the mind value map of Iran Airlines customers in relation to consuming drinks during flight to achieve a basis to conceptually design a product without alcohol but fulfilling the maximum satisfaction of customers.

Method: The present study is qualitative which uses Zaltman Metaphor Elicitation Technique (ZMET) projection method. The statistical population includes customers with 20 year old and higher age range of Iran Airlines that 15 participants involved in this matter selected based on saturation point logic through judgmental sampling. Then, data collected from questionnaires and interviews with semi-structured approach which was done on each sample and the content of data analyzed based on one of the customized models of means-end chain. Thus, key elements and the structures with the most repetition were extracted. Using Atlas T software, a consensus map of customers' minds was drawn.

Results: 4 elements at characteristics level, 13 elements at criteria level, and 14 elements at advantages and finally 3 elements at values level have been identified and they were prioritized for the target population.

Conclusion: This map helps achieving major variables in consuming target commodity in customers to clarify their consideration and decision making mental process. The results of this study are able to improve the expansion of products according to cultural ethical norms which satisfy customers and also future plans in serving air transportation market.

Keywords: Mind value map, Ethical marketing, Pseudo need, Non-alcoholic drink

* Corresponding Author: Email: naami122@yahoo.com

Received: 19 Jan 2021

Accepted: 20 Feb 2021

38

Available at: www.ijethics.com 


\section{Introduction}

Ethics is among the discussions with philosophical and anthropological bases which has entered business and marketing sciences aiming at maintaining and promoting human dignity. Ethical marketing is offering a product truly and really in the field of human, cultural and social values considered by consumers which has promoted the value of that product's customers. Ethical marketing includes a wide range from quality and price of commodity to the content of advertisement and distribution (1). Although, ethical issues are among the main challenges of marketing and the world is observing an everincreasing attention to the role of ethics in decision making and the behavior of consumer (2), the concepts of business ethics introduced from the beginning of 1980s in important commercial agencies and academic associations a new major called business ethics created in many important universities of the world and therefore, most of important economic institutes of the world prepared instructions to observe ethical points in their daily activities or behaving with their staff (3).

According to the previous studies, marketing ethics and professional ethics existed in many studies between during 1990 to 2013 (4). Before being considered in market and marketing strategies, ethical marketing is originated from philosophical and ethical fields. Therefore, defining ethical marketing and its principles necessitates understanding and comparing marketing ethics codes. Also, considering that ethical issues will contain a wider and more complicated dimensions, not preparing ethical regulations based on professional ethics rules will make comprehensively defining ethical marketing difficult in using ethical marketing methods. However, definitions from simple statements to more complicated expressions have been represented in this field. Business ethics has been introduced as a branch of applied ethics which investigates ethical and spiritual principles or ethical issues resulted from it in business environment (3). More comprehensively, marketing ethics refers to all activities re- lated to ethics in marketing in such a way that considers the benefits and advantages of all beneficiaries including organizations, customers, shareholders and society (5). The expansion of ethics in business world is not only about universal conventions and manifestos; but it is about real activities and personal commitments to enhance ethical standards (6). Policy makers need access, security and flexibility, fairness and honesty, performance and efficiency, compensation, accountability and trust in financial markets path (7). Also, deception, wrong information, refusal and or manipulating necessary information are among the common unethical marketing methods which lead to annoyance, disturbance and agitate consumers (8). What will help ethical marketing in the beginning is the description of values which influences decision making behavior of consumers. In other words, values defined as a set of individuals' desirable believes and principles which originated from the society, culture and believes of that individual and shows important considers in decision making processes of individual (9) therefore, even the values of staff may be strategized, managed and maintained in the ethical identity path of company (10). Generally, ethical marketing includes ethical codes and values effective on marketing methods which are incentives to create honesty and justice mixed with marketing and preventing insecure products, deceptive pricing, deceptive advertising and or bribery and discrimination in distribution (11). On the other hand, ethical values are in conflict at least with some businessman purposes and often with each other. Traditional utilitarianism simply states observing ethics about customer with satisfaction. Then, ethical principles mix with all priorities naturally, because ethical behaviors make general satisfaction overcomes personal behaviors. However, it is obvious that describing behavior appropriately depends on utilitarianism from a normal view and therefore, understanding the ethical nature of a product will necessitate much effort and it is not necessarily satisfactory for all (5). 
False needs and avoiding making or reinforcing them in customers is one of the concepts which are more obvious is this conflict and are explained at a deeper level of ethical marketing. In fact, this aspect has many difficulties because in addition to ignoring economic benefits for agency, it may dissatisfy some unaware customers. False needs are needs which are not originated from any objective reality but they are formed from baseless thoughts and dependencies which are made and followed for especial objectives (12). The concept of false needs appeared in the middle of $20^{\text {th }}$ century among scientists related to Frankfort School reacting to using advertising and marketing in the culture of consumer to produce desire and demand (13). This thought is based on this idea that people have been deviated under oppression influenced by cultural and ideological processes which prevent them understand the sources of pressure to make a movement opposite with the dominating trend. Satisfying false needs may be immediately pleasurable for people but they continue a social and mental oppression trend which finally includes all consumers and those who are acting to attract their attention. How deeply people feel their needs or they are satisfied is not important in this path. These needs follow external social needs that most of them are benefitted from influencing consumers with appearances including comfort, generosity, modernism and freedom. Most existing needs for relaxation, pleasure and consumption are taken from advertising in following others to love and hate the target product in this group (14). Radical critics even consider advertising mental washing activity which deepens society captivity against capitalism exploitation by stimulating false desires. Important characters like John Kenneth Galbraith, Herbert Marcuse, Raymond Williams, Guy Ernest Debord and many others have criticizing this approach in common (15). The ultimate purpose is making false needs for surplus and remarkable. Concepts like consumerism, commodity and preferences manipulation have turned into the main core of what is called the postmodernism criticism from society organization. The power of monopoly and advertising have been considered as a type of manipulation.
They interact by making personal identities to impose a system of values and preferences to consumers which is not natural and bases a consumption which is not supported by physiological, psychological and anthropological data. Consequently, selecting commodity and the consumption of customers will be mostly against fundamental needs. Consumers are in psychological denial in the bed of excessive consumption, recreational habits and commodities that tendency to them is useless. Personalized judgments are socially determined through cultural capital influencing a set of preferential fields which are called habitus, so consumers seek for discrimination through luxury consumption. Considering preferences manipulation, if customers experience these concepts naturally, personally and individually, there is such a discussion that force consumers to reduce the time appropriated for leisure time and enter working and spending cycle (16). But there is another aspect which is considering leisure time as consumerism. Private companies encourage us during leisure time to think about leisure time as an opportunity for example during strange holidays, eating abroad and etc. although differentiation is vague in two aspects of consumerism and leisure time, but preferences manipulation can be considered as reciprocal integration even in selecting leisure time forms which completes it (17).

Avoiding pseudo need may be included during different stages of early designing to commercialization and advertising product. The concept of desire has been considered more in more concentrated studies and it has been even substituted with need in some cases. Accordingly it is the relationship among need, demand and desire which activates the basis of ethical marketing. This is the difference between need and demand which shows the dimensions of desire (18). According to this view, human life has been formed around desire, the desire which is never satisfied and the desire which never covers the constitutive elements of issue. And this is exactly due to this reason that this is a constructive lack which may won't be filled by any "real" and "natural" thing. According to this view, desire and not achieving are always next to each other, and 
reduces human life dialectic concepts. So advertisements act according to tendency rules by stimulating or making our desire or a special part of it and there is no reason to refer this desire to the concept in a previous or prior need. Although advertisements are not fake (at least not in a direct way to damage the product which is advertised), they can stimulate or canalize a desire only by making a perfect legend about a product (19). Focusing on advertisement falsehood won't provide anything about how to accept their content by consumer. In fact, the relationship among production, consumption and discourse that advertising is a one of them is real and natural as much as it is. Therefore, focusing on the issue of reality/ falsehood is one of the most important obstacles in understating the performance of advertising, their desirable myths construction and sale and desire performance in the economics of market and capital (20).

Foodstuff is one of most important commodity groups or maybe the most important of all. Food and drink are important both from fundamental need aspect and from human rights aspect. So the judicial aspect of economic, social and cultural rights committee supervision institute has considered the main elements of this rights sufficiency, cultural acceptability, being healthy and economic and physical accessibility in interpreting food right materialization (21). Diet style may practically reflect religious, cultural, moral and philosophical items of people in cultural acceptability which shows differences in production of food and consumption. For example, there are aspects of religious orders and halal and haram in Judaism fasting rules which limits nutrition habits. Therefore, a food with a culture or religion makes taboo (forbidden) for receiver culturally unacceptable (3). Also, being free from any harmful things is one of the conditions which has to exist in the field of foodstuff health. Therefore, general and special methods ae to be developed to prevent foodstuff contamination and damage due to deception, weak management or weak environmental health during food production. Besides being forbidden in many cultures and believes, many studied have shown that alcoholic drinks are harmful for physical health
(22). However, drinking alcoholic drinks is pervasive due to economic and financial benefits during flight for airlines around the world so that there are only eight airlines which do not serve these drinks among so many international airlines with longrange flights in the world (23). So that drinking this type of drinks is forbidden due to individual and social harms in Islamic Republic of Iran Airlines. This may lose or dissatisfy some customers especially during international flights. Thus, offering new and creative drinks which have been designed or selected based on customers' original values and practical methods and instruments may influence in creating positive tendency and compensating customers' satisfaction.

\section{Material and Methods}

The present study is applied in purpose and is purely descriptive in content. Zaltman Metaphor Extraction Method (ZMET) used to collect data. Statistical population of this study are all "customers with 20 year old and higher age range of Iran Airlines". Research territory considered soft drinks which are served cold. 15 selected based on saturation point and through judgmental sampling. Personal Involvement Inventory (PII) developed by Zaichkowsky (1985) was research instrument in this study and the interview was semi-structured. PII has 20 questions which is placed on semantic differentiation 7-item scale which measures personal mental involvement with commodity or service.it is suggested that high involvement with product be in 111-140 scores scale (10). Therefore, participants with 111 or higher score selected for interview.

The instruction was that the participants received the subject and instruction of participating in session through email before interview to get ready to take part in interview session. The subject of session which is achieving the dimensions of consuming drinks behavior during flight explained in this instruction and participants were asked to gather 8 to 10 images from internet, books, personal album, newspapers and magazines and other resources which show or are related to the subject and demonstrate their emotions and thoughts about 
this subject. The important point is that these picture must not show the image of drink consuming it. Personal interviews conducted around 7 to 10 days later. Each interview takes around 2 hours. The following steps performed in this regard:

- Each interviewee asked to explain why he has selected this image and what the content of the considered image is.

- The interviewee was asked that what image could be added to this collection and with what content but he has not found the considered picture.

- The respondent was asked to extend image frame and explain what can be added to the image to make his thoughts and emptions be perceived.

- The respondent was asked to express their ideas using emotional indices of color, taste, smell, touch, sound and different emotions.

- The respondent was asked to make a summarized collage using his own images and supplementary images from database by means of a computer illustrator.

A customized model of means-end chain theory used to analyze this study. This method arranges decision making process and also infrastructural motivations and values which are expected by the consumers (24). According to this frame, communications between objective or subjective features of the product are expressed as means to educational values (purposes) through consequences which are defined by functional and mental advantages (25). Consequences are the self-conscious reasons of individual to use the product while, values are the ultimate goal and the highest level of chain and individual may not notice them during consumption but he has inclined to use them in his subconscious with these major purposes (26). In cognitive approach, the consumer is supposed to arrange the expressed preference for features as well as creating advantages and values in a hierarchal way. This is supported by experimental hypotheses which are used to evaluate respondents' output for related features in ladder test (27). Major paths expected in consuming foodstuff includes: hedonic enjoyment, satisfaction and good performance. Therefore, these three performances are influential in consumption conditions in consumer decision making to continue consuming or stopping that foodstuff. Figure 1 shows behavioral logic structure in foodstuff market.

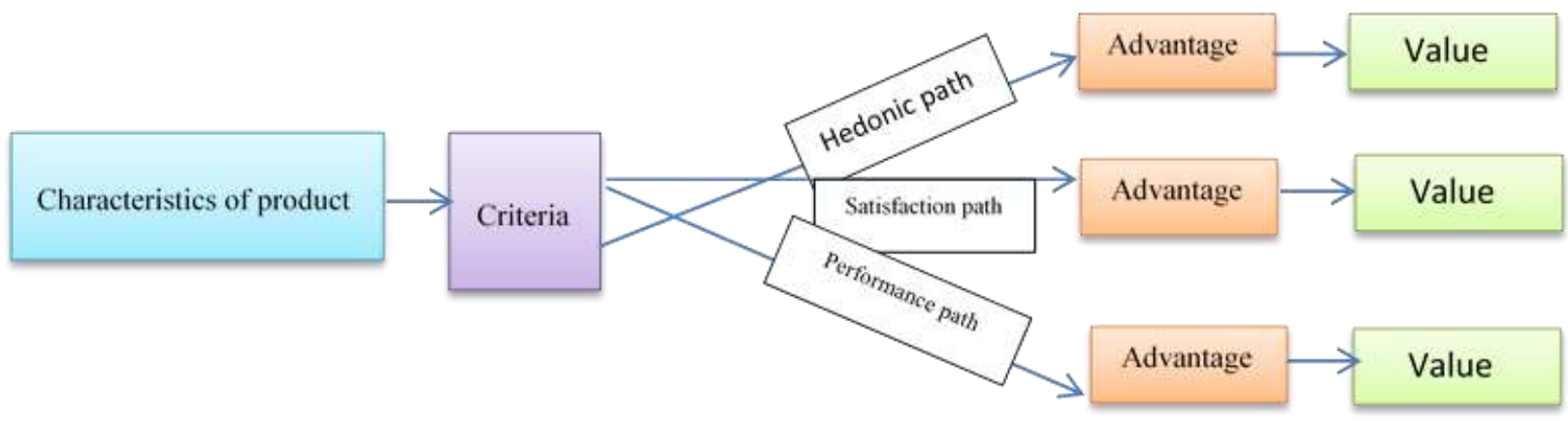

Figure 1: Behavioral logic structure in foodstuff market (28)

\section{Results}

The process of interview stages conducted on all images as well as lost images and collages added to them. When interviews finished and recorded, they were coded and codes with close similarity were merged with each other. Based on this and using the related literature, codes were classified in a way that product characteristics (1) labeled with (2) criteria, (3) consequences and (4) values. In order to ensure the correctness of structures coding and classification, the structures grouped in two separated classifications by analyzing them repeatedly by two researchers separately. Elements that more than one third of respondents have mentioned 
Naami A. et al.

them and structures (relationships between elements) that more than one fourth of respondents have mentioned them have had theoretical saturation and may enter the final map. Therefore, ele- ments with at least six times repetition and structures (relationships) which have been mentioned at least four times entered the final map. Accordingly, table 1 shows 33 final extracted elements.

Table1: elements extracted from interviews

\begin{tabular}{|c|c|c|c|c|c|}
\hline Label & Element & Time of repetition & Label & \multicolumn{2}{c|}{ Element } \\
\hline 2 & Flavor enhancer & 13 & 1 & Mouth-coating & 10 \\
\hline 2 & Carbonation & 12 & 2 & Sweetness & 14 \\
\hline 3 & Peace & 7 & 1 & Taste (deliciousness) & 15 \\
\hline 3 & Feel assurance & 11 & 2 & Fattiness & 2 \\
\hline 3 & Curiosity & 9 & 4 & Enjoyment & 12 \\
\hline 3 & Problem solving & 6 & 2 & Acidity & 7 \\
\hline 3 & Belonging to group & 7 & 3 & Filling & 6 \\
\hline 1 & Appearance & 14 & 1 & Odor and smell & 7 \\
\hline 2 & Combination steadiness & 3 & 2 & Glassiness & 11 \\
\hline 2 & Bitterness & 6 & 2 & Astringency & 8 \\
\hline 2 & Concentration & 10 & 2 & Saltiness & 6 \\
\hline 2 & Spikiness & 8 & 3 & Self-esteem & 10 \\
\hline 3 & Healthiness & 10 & 2 & Mouth-coating & 8 \\
\hline 2 & Color intensity & 11 & 3 & Easy consumption & 9 \\
\hline 2 & Viscosity (syrup) & 4 & 4 & Good performance & 10 \\
\hline 3 & Thirst quenching & 9 & 3 & Complexity & 13 \\
\hline 3 & Naturalness & 9 & 3 & Family experiences & 11 \\
\hline 4 & Satisfaction & 15 & 3 & Quality & 15 \\
\hline
\end{tabular}

Also table 2 investigated the existence and repetition of causative relations aiming at extracting structures.

At last, the common mental value map drawn using mean-end chain theory in such a way that the characteristics of product placed in first class, criteria in the second class, consequences (advantages) in the third class and values placed in the fourth class. Figure 2 shows this map resulted from Atlas T.

Table 2: the existence and repetition of formed structures

\begin{tabular}{|c|c|c|c|c|c|c|c|}
\hline Row & $\begin{array}{l}\text { Exogenous } \\
\text { variable }\end{array}$ & $\begin{array}{c}\text { Endogenous } \\
\text { variable }\end{array}$ & $\begin{array}{l}\text { Time of } \\
\text { repetition }\end{array}$ & Row & $\begin{array}{c}\text { Exogenous var- } \\
\text { iable }\end{array}$ & $\begin{array}{c}\text { Endogenous } \\
\text { variable }\end{array}$ & $\begin{array}{l}\text { Time of } \\
\text { repetition }\end{array}$ \\
\hline 1 & Taste (deliciousness) & Flavor enhancer & 10 & 36 & Flavor enhancer & Quality & 5 \\
\hline 2 & Taste (deliciousness) & Sweetness & 8 & 37 & Carbonation & Complexity & 13 \\
\hline 3 & Taste (deliciousness) & Acidity & 6 & 38 & Carbonation & Quality & 6 \\
\hline 4 & Taste (deliciousness) & Bitterness & 8 & 39 & Carbonation & Thirst quenching & 6 \\
\hline 5 & Taste (deliciousness) & Spikiness & 4 & 40 & Carbonation & Belonging to group & 5 \\
\hline 6 & Taste (deliciousness) & Saltiness & 5 & 41 & Astringency & Complexity & 9 \\
\hline 7 & Taste (deliciousness) & Naturalness & 9 & 42 & Concentration & Quality & 8 \\
\hline 8 & Appearance & Glassiness & 14 & 43 & Acidity & Quality & 5 \\
\hline 9 & Appearance & Color intensity & 11 & 44 & Glassiness & Quality & 10 \\
\hline 10 & Appearance & Concentration & 8 & 45 & Glassiness & Healthiness & 11 \\
\hline 11 & Appearance & Naturalness & 8 & 46 & Color intensity & Quality & 8 \\
\hline 12 & Appearance & Curiosity & 6 & 47 & Color intensity & Naturalness & 6 \\
\hline 13 & Appearance & Complexity & 2 & 48 & Mouth-coating & Complexity & 14 \\
\hline 14 & Odor and smell & Curiosity & 8 & 49 & Sweetness & Healthiness & 8 \\
\hline 15 & Odor and smell & Naturalness & 6 & 50 & Sweetness & Naturalness & 3 \\
\hline 16 & Odor and smell & Complexity & 3 & 51 & Sweetness & Quality & 11 \\
\hline 17 & Odor and smell & Refreshing & 13 & 52 & Sweetness & Filling & 6 \\
\hline 18 & Mouth-coating & Mouth-coating & 15 & 53 & Spikiness & Quality & 5 \\
\hline 19 & Mouth-coating & Naturalness & 10 & 54 & Spikiness & Curiosity & 5 \\
\hline
\end{tabular}


Naami A. et al.

International Journal of Ethics \& Society (IJES), (2021) Vol. 2, No. 4

\begin{tabular}{|c|c|c|c|c|c|c|c|}
\hline 20 & Mouth-coating & Concentration & 5 & 55 & Bitterness & Complexity & 10 \\
\hline 21 & Mouth-coating & Astringency & 14 & 56 & Bitterness & Thirst quenching & 11 \\
\hline 22 & Mouth-coating & Carbonation & 15 & 57 & Bitterness & Quality & 8 \\
\hline 23 & Mouth-coating & Complexity & 18 & 58 & Saltiness & Quality & 5 \\
\hline 24 & Filling & Good performance & 13 & 59 & Thirst quenching & Good performance & 7 \\
\hline 25 & Family experiences & Enjoyment & 15 & 60 & Thirst quenching & Problem solving & 9 \\
\hline 26 & Family experiences & Peace & 17 & 61 & Thirst quenching & Enjoyment & 14 \\
\hline 27 & Peace & Satisfaction & 9 & 62 & Problem solving & Satisfaction & 11 \\
\hline 28 & Quality & Satisfaction & 11 & 63 & Refreshing & Enjoyment & 15 \\
\hline 29 & Quality & Enjoyment & 3 & 64 & Curiosity & Enjoyment & 10 \\
\hline 30 & Quality & Good performance & 8 & 65 & Curiosity & Satisfaction & 2 \\
\hline 31 & Feel assurance & Satisfaction & 18 & 66 & Curiosity & Self-esteem & 6 \\
\hline 32 & Complexity & Curiosity & 7 & 67 & Naturalness & Healthiness & 18 \\
\hline 33 & Healthiness & Quality & 3 & 68 & Naturalness & Satisfaction & 16 \\
\hline 34 & Healthiness & Feel assurance & 12 & 69 & odor and smell & Odor intensity & 8 \\
\hline 35 & Self-esteem & Satisfaction & 10 & 70 & Odor intensity & Naturalness & 5 \\
\hline
\end{tabular}

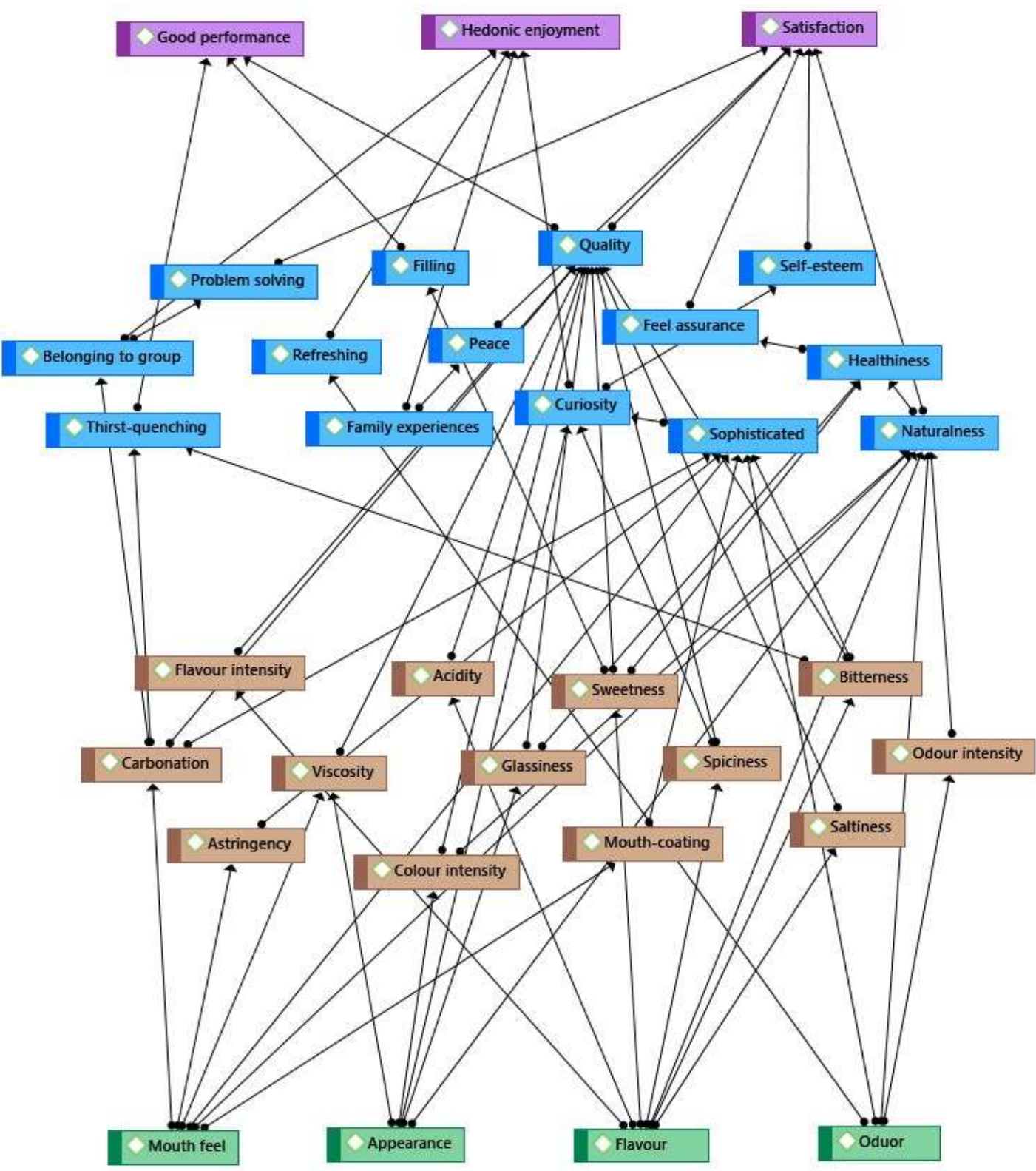

Figure 2: Customers' hierarchal value map

Available at: www.ijethics.com 
Green is the elements of product characteristics class, brown is the elements of product criteria class, blue is the elements of product consequences class and purple is the elements of product values class.

\section{Discussion}

The extracted map of customers' value shows that four characteristics of product, taste (deliciousness) and appearance and smell and odor and sense formed in mouth are the bases of value map. Among these characteristics, the characteristics of taste (deliciousness) with 7 exogenesises is the most important characteristics in customers' point of view. After taste, sense formed in mouth is in the second rank with 6 exogenesises and then appearance with 5 exogenesises and odor and smell with 4 exogenesises are in the next ranks. Criteria are elements that the one who judges, comments in characteristics by measuring them. 13 elements as criterion for customers extracted in this study that among them, carbonation with 3 exogenesises and then sweetness with 2 exogenesises and bitterness with 2 exogenesises are more influential than other criteria. Then the rest of criteria including: acidity, astringency, glassiness, tastefulness, spikiness, saltiness, color intensity, mouth-coating and odor intensity are in the same rank. Quality is the most considerable element in consequences class where exogenesis is important. Quality with 12 exogenesises has the most consequence and advantage that customers follow it. After quality, naturalness with 8 exogenesises is important which is considerable. Then, there are complexity with 7 exogenesises and then curiosity and thirst quenching with 2 exogenesises. Other consequence are almost in the same level. In values class where exogenesis is important, satisfaction is a value which has occupied customers' mind more than other elements. Satisfaction has 6 exogenesises which is considerable than other values. After satisfaction, there is enjoyment with 4 exogenesises which shows that this value is still important is customers' decision making. Finally, good performance with 3 exogenesises is another value that customers expect from consuming drinks during flight. Thus, variables effective on each level of travelers' interest in consuming drinks during flight are identified and prioritized through mapping customer's hierarchal mental value. Based on the studies conducted by the researcher no similar study has been found but there are many studies in ethical marketing that confirm the total result of the present study that is the effectiveness of customers' mental value on their behavior (29-32).

It is gusted that considering the tendency of some unaware customers to harmful products, it is possible to inform them continuously and promoting the product creatively as parallel as the activities of introducing and offering product. At last the results of this study may be used to do marketing activities from ideation and designing to advertising target products and also they may help improving future programming in serving the considered market.

\section{Conclusion}

This study generally aims at recognizing original factors and influential values on customers' behavior in selecting and consuming drinks and clarifying their decision making pattern in this field. Aiming at this objecting leads to offering a product which besides supplying the financial resources of the considered agency in economic activities, be culturally and ideologically acceptable based on the principles of ethical marketing and be appropriate with personal and social values and also has considered healthiness and harmfulness of the product. On the other hand, not promoting alcoholic drinks common in air transportation industry besides trying to avoid making and reinforcing false and harmful needs for customers, considers ethics normal aspects in Iran.

\section{Ethical Consideration}

Moral issues (such as plagiarism, conscious satisfaction, misleading, making and or forging data, publishing or sending to two places, redundancy and etc.) have been fully considered by the writers. 


\section{Acknowledgement}

Researchers consider it necessary to thank and appreciate all the participants who helped us in this research.

\section{References}

1. Mosleh A, Allahyari-Buzarjani A (2010). Ethics in marketing: ethical values emphasized by Islam in the management of marketing activities. Quarterly Journal of Ethics Research, 8: 57-73. (In Persian).

2. Ajorloo F, Agheli M, Moslemi Kaviri M (2020). Factors related to the ethical selection of food products. Ethics in science and Technology, 14 (5):133-141. (In Persian).

3. Cardello AV (1996). The role of the buman senses in food acceptance. In: Meiselman HL, MacFie HJH. (Eds). Food Choice Acceptance and Consumption. Blackie Academic and Professional, Glasgow/UK. Pp. 1-82.

4. Javalgi RG, Russell LTM (2015). International marketing ethics: a literature review and research agenda. Journal of Business Ethics, 1-18.

5. Jones MO (2005). Food choice, symbolism, and identity: Bread and butter issues for folkloristic and nutrition studies. Journal of American Folkelore, 120(470):129-177.

6. Lagerkvist C, Okello J, Karanja N (2015). Consumers' mental model of food safety for fresh vegetables in Nairobi. British Food Journal, 117 (1): 22-36.

7. Quandt SA, Arcury TA, Bell RA, McDonald J, Vitolins M $\mathrm{Z}$ (2001). The social and nutritional meaning of food sharing among older rural adults. Journal of Aging Studies, 15 (2):145-162.

8. ÖzbekVolkan, Alnıaçık Ümit, Akkılıç Emin, Koç Fatih (2013). The moderating role of locus of control on the links between perceived ethical problem and ethical intentions of marketing managers in Turkey. Procedia -Social and Behavioral Sciences, (99): 265-273.

9. Bisogni CA, Connors M, Devine CM, Sobal J (2002). Who we are and how we eat: A qualitative study of identities in food choice. Journal of Nutrition Education and Behavior, 34(3):128-139.

10. Christensen GL, Olson JC (2002). Mapping consumers' mental models with ZMET". Journal of Psychology and Marketing, 19(0): 477-502

11. Stroebe W, Papies EK, Aarts H (2008). From homeostatic to hedonic theories of eating: Self-regulatory failure in food-rich environments. Applied Psychology, 57:172-193
12. Hamzeian E, Zangian S, Sharafi V, Akbarzadeh M (2015). Analysis of marketing types from the perspective of normative ethics ethics. Jounnal of ethical Researches, 6(1):117-135. (In Persian).

13. Thorsen LE (1991). Norwegian farm women and the cultural meaning of food. Journal of Rural Studies, 7 (1, 2): 63 66.

14. Ryu K, Han H, Jang S (2010). Relationships among hedonic and utilitarian values, satisfaction and behavioral intentions in the fast-casual restaurant industry. International Journal of Contemporary Hospitality Management, 22 (3): 416432.

15. Stroebele N, DE Castro JM (2004). Effect of ambience on food intake and food choice. Nutrition, 20: 821-838.

16. Zanoli R, Naspetti S (2002). Consumer motivations in the purchase of organic food. A means-end approach. British Food Journal, 104 (8): 643-653.

17. Wansik B (2004). Environmental factors that increase the food intake and consumption volume of unknowing consumers. Annual Reviens in Nutrition, 24: 455-479.

18. Zaltman G (2003). How customers think: essential insights into the mind of the market. Harvard Business School Press, Boston.

19. Yang Elaine C, Khoo-Lattimore C (2015). Food and the perception of eating: the case of young Taiwanese consumers. Asia Pacific Journal of Tourism Research, 20(1).

20. Zaltman G (1997). Rethinking market research: putting people back in. Journal of Marketing Research, 34(4): 424-437.

21. Zaltman G, Coulter RH (1995). Seeing the voice of the customer: metaphor-based advertising research. Journal of Advertising Research, (July/August): 35-51.

22. Chen MF (2011). Consumer's trust-in-food-safety typology in Taiwan: Food-related lifestyle matters. Health, Risk and Society, 13 (6): 503-526

23. Chen P (2006). Sport tourists' loyalty: a conceptual model. Journal of Sport and Tourism, 11 (3, 4): 201-237.

24. Xiao L, Guo Z, D’Ambra J (2017). Analyzing consumer goal structure in online group buying: A means-end chain approach. Information and Management, 54 (8): 1097-1119.

25. Kim B, Kim SS, King B (2016). The sacred and the profane: Identifying pilgrim traveler value orientations using means-end theory. Tourism Management, 56: 142-155

26. Bakhshizadeh K, Haijiafar A, Nasiri H (2019). Eliciting mental map of the customers of Digikala E-stores using zaltman metaphor elicitation technique (ZMET). Journal of Business Management, 10(1): 49-72. (In Persian).

27. Shakeri R, Khanlari A (2016). Understanding the brand image using Zaltman's metaphor extraction method. Journal of Business Management Perspective, 24: 155-170.

28. MacFie H (2007). Consumer-led food product development. Wood head Publishing, USA. 
29. Lusk JL, Briggeman BC (2009). Food values. American Journal of Agricultural Economics, 91 (1): 184-196

30. Warde A, Martens L (2000) Eating out: Social differentiation, consumption and pleasure. Cambridge University Press, Cambridge/UK.
31. Van Kleef E, Van Trïp HCM, Luning P (2005). Consumer research in the early stages of new product development: a critical review of methods and techniques. Food Quality and Preference, 16:181-202.

32. Rozin P (1996b). Towards a psychology of food and eating. From motivation to module to model to marker, morality, meaning, and metaphor. Current Directions in Pyychological Science, 5 (1):18-24. 